\title{
CISTO DERMÓIDE NA REGIÃO DO BREGMA: RELATO DE DOIS CASOS
}

\author{
Walter C. Pereira* \\ Almir F. ANdrade ** Pedro G. Lopes **
}

O cisto dermóide é um tumor constituído por tecidos derivados do ecto e mesoderma, localizando-se preferentemente nas linhas de fechamento das fissuras embrionárias primitivas. Embora possa ocorrer no interior das cavidades orgânicas, acometendo os mais variados órgãos, o cisto dermóide, na grande maioria das vêzes, situa-se superficialmente sob as camadas cutânea e subcutânea. Quase sempre é encontrado na linha mediana, máxime na região sacrococcigea, podendo, contudo, situar-se nas faces laterais do pescoço, cauda dos supercílios, ducto tireoglosso e em muitos outros locais ${ }^{1,2,4}$. Tanto a localização extra como a intracraniana são raramente assinaladas.

$O$ relato de dois casos recentemente observados reveste-se de interêsse porquanto, em ambos, o diagnóstico pré-operatório foi de meningencefalocele devido à situação mediana da tumoração cística sôbre a fontanela bregmática.

\section{O B SER V A ÇÓ E S}

J.C.G. (registro HC 774920) e M.F.G. (registro HC 861694), ambos do sexo masculino e de côr branca, com 8 e 4 meses de idade, respectivamente, não sendo irmãos. Os pais referiam, nos dois casos, que logo após o nascimento haviam notado a presença de massas tumorais arredondadas localizadas ao nivel da fontanela anterior. Inicialmente eram de pequenas dimensões, porém aumentaram rảpidamente de volume com o crescimento das criancas, atingindo $6 \mathrm{~cm}$ (J.C.G.) e $7 \mathrm{~cm}$ (M.F.G.) de diâmetro por ocasião da internação (Fig. 1). Os exames clínico e neurológico eram inteiramente normals $e$ as dimensōes cranianas estavam dentro dos limites da normalidade nas duas crianças. O exame local mostrava tumorações de consistência homogêneamente cística; a tensão aumentava ligeiramente com o chôro; a palpação era indolor, sendo as massas tumorais fixas aos planos profundos; a pele que as recobria apresentava aspecto, consistência e coloração normais, sendo normalmente recoberta de pêlos; a transiluminação demonstrou que o conteúdo era homogêneo e aparentemente líquido. Craniogramas, feitos em ambas as crianças, revelaram erosão da tábua externa ao nivel das tumorações, não sendo possível identificar solução de continuidade óssea além da fontanela bregmática. O estudo angiográfico cerebral, via artéria carótida direita, mostrou vasos arteriais e venosos com calibre e topografia normais, inclusive o seio sagital superior.

Departamento de Neurologia da Faculdade de Medicina da Universidade de São Paulo (Prof. Adherbal Tolosa): * Neurocirurgião; ** Estagiários de neurocirurgia. 


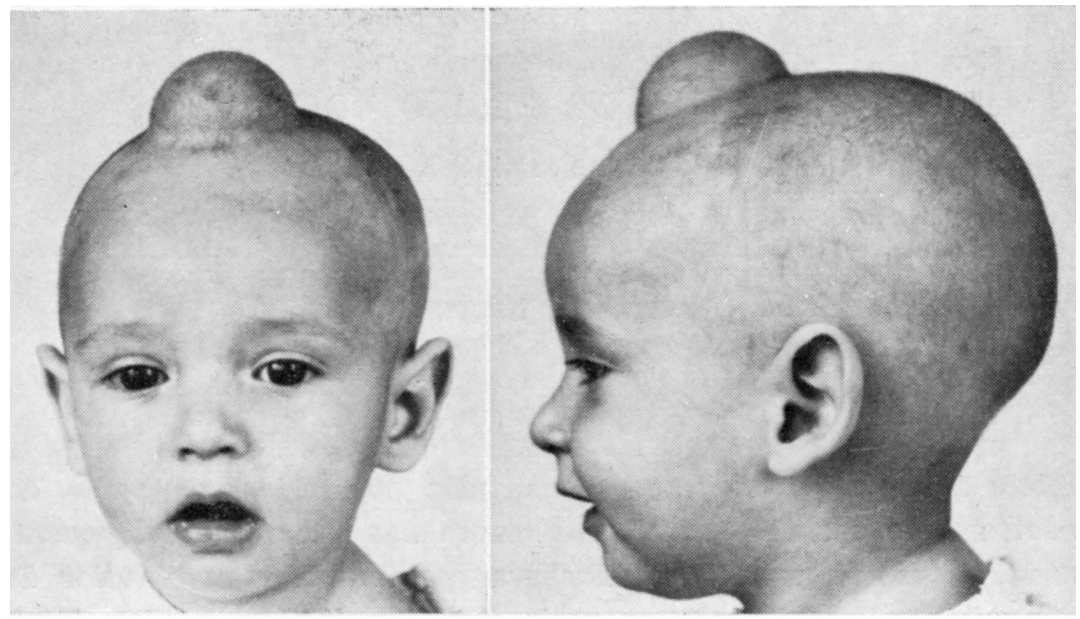

Fig. 1 - Fotografias de frente e perfil do paciente J.C.G., mostrando a localizacão do cisto dermóide.

Ambos os pacientes foram operados com a suspeita clínica de meningencefalocele. Após a abertura da pele, mediante incisão transversal, encontrou-se tumor cístico recoberto por cápsula translúcida ricamente vascularizada (fig. 2). A dissecção de tôda a periferia das tumorações foi muito fácil, pois não havia aderências firmes com os tecidos moles ou com a calota craniana; esta se apresentava erosada e muito fina, em ambos os casos, porém não foi encontrada solução de continuidade alguma. As peças cirúrgicas foram encaminhadas para exame histopatológico, tendo êste revelado a estrutura típica do cisto dermóide. O pós-operatório decorreu sem qualquer complicação, tendo ambos os pacientes recebido alta curados.

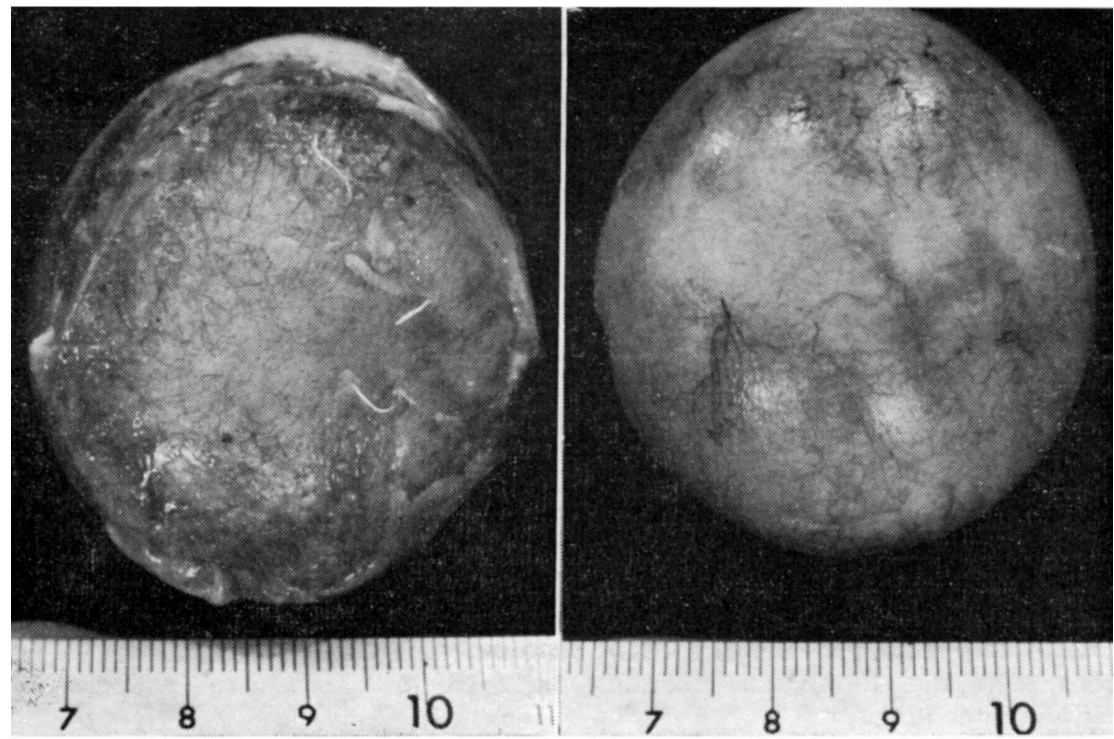

Fig. 2 - Aspectos macroscópicos do tumor (caso J.C.G.). Notar a superficie brilhante e ricamente vascularizada. 


\section{COM ENTÁR I OS}

Os dois casos ora relatados apresentavam grande semelhança do ponto de vista clínico como em relação aos resultados do exame radiológico. Em ambos a situação mediana do processo cístico sôbre a fontanela bregmática sugeriu o diagnóstico inicial de meningencefalocele, a qual nesta região é muito rara ${ }^{3,5}$. Sòmente após a intervenção cirúrgica é que a verdadeira natureza do tumor foi determinada. Acreditamos que, de ora em diante, com a atenção voltada para a possível confusão, tenhamos elementos úteis para melhor orientar o diagnóstico diferencial. Nos dois casos apresentados o exame neurológico era inteiramente normal, o que raramente sucede em doentes com meningencefalocele. Além disso, a angiografia cerebral não revelou sinais de dilatação ventricular nem desvios ou anomalias do seio sagital superior, achados que possìvelmente ocorreriam caso realmente se tratasse de meningencefaloceles. Tais dados, portanto, deverão ser valorizados para a elucidação clínica de casos futuros.

\section{R E S U M O}

São relatados dois casos de cisto dermóide extracranianos situados sôbre a fontanela bregmática em meninos de 4 e 8 meses de idade. $\mathrm{O}$ diagnóstico pré-operatório em ambos havia sido de meningencefalocele. Os autores chamam a atenção para a normalidade do exame neurológico e da angiografia cerebral nos dois pacientes, dados que devem ser valorizados para o diagnóstico diferencial de casos futuros.

\section{S U M M A R Y}

\section{Bregmatic dermoid cyst: report of two cases.}

Two cases of extracranial dermoid cysts located upon the bregmatic fontanel in 4 and 8-month-old male children are reported. The preoperative diagnosis in both cases was meningoencephalocele. The authors emphasize the normality of the neurologic and angiographic findings in the two patients; these features will be remembered in the differential diagnosis in further cases.

REFER E N I A S

1. ALLEN, A. C. - The Skin. Willian Heinemann, London, ed. 2, 1967.

2. Bechelli, L. M. \& CURBAN, G. V. - Compêndio de Dermatologia, Atheneu, São Paulo, 2.a ed., 1963.

3. BAKER, A. B. - Clinical Neurology. Hoeber-Harper, ed. 2, 1962. 
352 ARQ. NEURO-PSIQUIAT. (SÃO PAULO) VOL. 27, N.० 4, DEZEMBRO, 1969

4. BOYD, W. - Compêndio de Patologia Geral e de Anatomia Patológica. Trad. por C. Magarino Torres e A. Penna de Azevedo, Koogan, Guanabara, 1954.

5. INGRAHAM, F. D. \& MATSON, D. D. - Neurosurgery of the Infancy and Childhood. Charles C. Thomas, Springfield (Illinois), 1954.

Departamento de Neurologia - Faculdade de Medicina da Universidade de São Paulo - Caixa Postal 3461 - São Paulo, SP — Brasil. 